\title{
УПРАВЛЕНИЕ ОБРАЗОВАНИЕМ
}

УДК $37.014+352.075$

Т. Е. Зерчанинова,

Т. В. Зубарева

СОЦИАЛЬНЫЙ АУДИТ РАЗВИТИЯ МУНИЦИПАЛЬНОЙ СИСТЕМЫ ОБЩЕГО ОБРАЗОВАНИЯ

Аннотаиия. Статья посвящена проблемам стратегического управмения муниципальной системой общего образования. Дия того чтобы максимально точно определить ближайшие и отдаленные перспективы развития данной системы, авторы разработали концептуальную модель ее социального аудита.

На основе материалов о деятельности органов местного самоуправмения Березовского городского округа Свердмовской области описывается процедура подобного аудита, включающая четыре этапа: предметно-содержательный анализ муниципальных документов о стратегии развития общего образования; диагностику состояния и проблем его развития; оценку эффективности и темпов развития общего образования на муниципальном уровне; разработку практических рекомендаций по улучшению качества образования. Проведенный аудит показал: процесс и реультаты образования отслеживаются бессистемно, что мешает своевременно вносить необходимые коррективы в осуществляемую работу.

Дия решения выявленных недостатков предложен ряд мер: совершенствование кадровой работы, создание управленческого резерва на уровне области и проведение управленческих практикумов, повышение информированности педагогов о современных средствах обучения, внесение существенных дополнений в городскую целевую программу «Развитие системы образования Березовского городского округа на 20112015 гг.». Однако эти предложения направлены в основном на устранение текущих проблем и не ориентированы на вызовы завтрашнего дня, на стратегию опережения. В целях устойчивого развития муниципальной системы образования, по мнению авторов, необходимо перенести акцент с укрепления инфраструктуры на достижение нового качества образовательных услуг. 
Ключевые слова: муниципальная система образования, социальный аудит, эффективность.

Abstract. The paper deals with the theory and practice of social audit of the municipal system of general education. The authors have developed a conceptual model of social audit to accurately identify both the short- and long-term development prospects of the given system. The paper describes the social audit procedures in Berezovsky municipal district of Sverdlovsk region including four stages: the content analysis of municipal documents concerning the development strategy of the general education system, diagnosis of the current conditions and problems, effectiveness evaluation of the municipal system of general education, and practical recommendations for improving the education quality. The above mentioned audit demonstrates that the indices of education development are unsystematically tracked, obstructing therefore the adjustment process. To solve the given problems the following measures are recommended: personnel policy development, creating the regional managerial reserve and organizing management workshops, informing the teachers about the modern educational tools, and updating the municipal program of the "Educational System Development of Berezovsky Municipal District for 20011-20015". However, the above suggestions target only the current problems disregarding the challenges of tomorrow which require the advancing strategy. In authors' opinion, the main emphasis should be replaced on the quality improvement of the municipal educational services instead of the infrastructure reinforcement.

Keywords: municipal system of education, social audit, effectiveness.

Развитие муниципальных систем общего образования характеризуется целым рядом тенденций. Во-первых, изменения в экономике, возникновение новых технологий выдвигают более высокие требования со стороны общества и государства к подготовке подрастающего поколения, что говорит о необходимости модернизации системы общего образования, введении инноваций, в том числе на муниципальном уровне. Во-вторых, формируются новые требования к системе образования со стороны других субъектов образовательного процесса - учащихся и их родителей (законных представителей). В-третьих, обнаруживается и продолжает проявмяться существенная разница условий для развития образовательных систем в различных субъектах Российской Федерации и в муниципальных образованиях. 
Причины обостряющихся проблем общего образования - «ухудшение качества педагогического корпуса, рост межрегиональных и межшкольных размичий в качестве образования, стагнация системы дополнительного образования и воспитания. Образование перестало выполнять функцию социального мифта, оно начинает воспроизводить и закреплять социальную дифференциацию. Сеть образовательных учреждений не соответствует особенностям расселения, а содержание и формы образования - изменившимся запросам общества. При этом механизм единовременного обновмения содержания образования через введение новых стандартов не работает" [11, с. 268].

В сложившейся ситуации особую актуальность приобретают исследовательский поиск и внедрение механизмов стратегического управления муниципальными системами общего образования. Органам местного самоуправцения необходимо переключиться с режима обеспечения функционирования этих систем на режим проектирования и поддержки их развития. Четкие формулировки цемей на долгосрочную перспективу могли бы во многом облегчить процесс обновления общего образования. К сожалению, технология стратегического управления, активно использующаяся на государственном и муниципальном уровнях для развития территории в целом, пока редко применяется в отношении отдельных отрасмей, в том числе образования.

С философской точки зрения, развитие - это "необратимое, направленное, закономерное изменение материальных и идеальных объектов... В результате развития возникает новое качественное состояние объекта, которое выступает как изменение его состава или структуры (т. е. возникновение, трансформация или исчезновение его эмементов или связей)" [13]. Идея развития стала центральной в некоторых социологических теориях, которые можно объединить под названием "теория развития". Социальное развитие - это «форма, раскрывающая потенциал, который изначально заложен в системе" [12, с. 25]. Развитие сопровождается качественными внутрисистемными преобразованиями или привнесением в систему новых элементов и связей, изменяющих содержание и характер функционирования системы. Таким образом, развитие муниципальной системы общего образования можно опре- 
делить как процесс ее перехода к новому качественному состоянию, сопровождающийся качественными внутрисистемными преобразованиями или привнесением в систему новых эмементов и связей, изменяющих ее содержание и характер функционирования, и раскрывающий заложенный в системе потенциал.

Развитие общего образования - необходимое условие достижения долговременных результатов и, соответственно, эффективного функционирования всей социальной системы в долгосрочной перспективе. При разработке стратегии развития образования обязательно должны учитываться все негативные и положительные реалии времени: набирающий силу кризис традиционной модели детства, утрата формальным образованием ведущей роли в воспитании и социализации детей, разрушение всеобщих культурных ценностей, становцение нового технологического уклада и т. д. Нельзя не согласиться с горькой констатацией: "Глобальные вызовы образованию завтрашнего дня: школа утратила монопомию на образование и социализацию детей и не умеет опираться на изменившиеся механизмы взросления и семейного воспитания. Система образования не успевает обновцяться, чтобы отвечать на технологические, культурные и социальные изменения, на новые потребности семей и детей” [11, с. 268].

ДАя того чтобы максимально точно определить перспективы развития муниципальной системы общего образования, мы предмагаем такую исследовательскую технологию, как социальный аудит, которая рассматривается нами как вид социоинженерной деятельности, вкАючающий социальную диагностику состояния данной системы, оценку социальной эффективности деятельности органов местного самоуправцения в сфере образования и консуцьтационную поддержку этих органов по мерам развития общего образования.

Нами разработана концептуальная модель социального аудита, в которой использованы отдельные положения Концепции российской модели социального аудита [5]. Однако наша модель наполнена новым содержанием, адаптированным к муниципальному управлению и к социологическим методам исследования. Структура модели представлена на рисунке. 
Соџиальный аудит развития мунищипальной системы общего образования

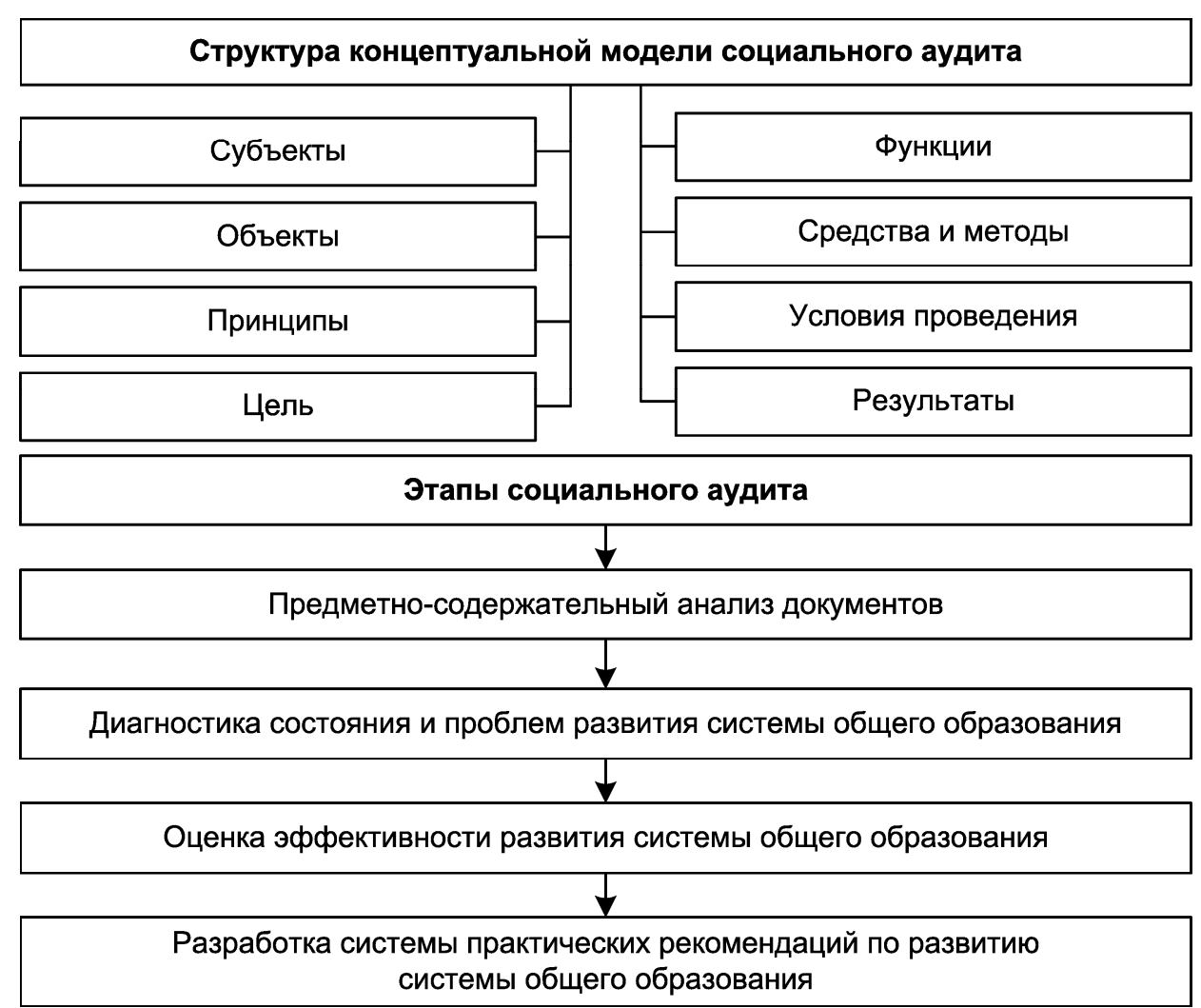

Концептуальная модель социального аудита

Рассмотрим элементы предлагаемой модели.

1. Субъектами социального аудита развития муниципальной системы общего образования являются заказчики такого аудита (органы государственной вцасти и органы местного самоуправмения, политические партии, общественные организации и другие институты гражданского общества) и исполнители (научно-исследовательские комлективы, организации, отдельные ученые).

2. Объект аудита- деятельность органов местного самоуправления в сфере общего образования.

3. Основные приниипы - добровольность, рекомендательный характер, независимость социальных аудиторов от заказчиков, открытость и достоверность результатов аудита, профессионализм его исполнителей. 
4. Целью социального аудита в нашем случае становится оценка эффективности работы органов местного самоуправления в сфере общего образования и разработка управленческих технологий по совершенствованию этой работы, повышению ее качества и результативности.

5. Функиии аудита: диагностическая, оценочная, корректирующая, обеспечение обратной связи, регулирование взаимодействия между органами вмасти, общественными организациями и институтами гражданского общества.

6. Средства аудита делятся на познавательные (методы исследовательской деятельности) и предметные (компьютеры, оргтехника, канцелярия). Его методы могут быть разделены на две группы:

1) теоретические: описание, анализ, синтез, модемирование, измерение, сравнение, классификация, типология;

2) эмпирические: анализ официальных документов, социологический опрос населения, фокус-группа, экспертные методы, эвристические методы, анализ статистических показателей.

7. Условия, в которых осуществляется аудит, - это компцекс характеристик среды, где осуществляется деятельность. "Инвариантным для мюбой деятельности является следующий набор групп условий: мотивационные, кадровые, материально-технические, научно-методические, финансовые, организационные, нормативно-правовые, информационные условия" [6]. К представленному А. М. Новиковым и Д. А. Новиковым перечню мы бы добавили психологические условия, а также условия макросреды - политические, экономические, социальные.

8. Результаты социального аудита включают итоги социальной диагностики, оценку эффективности деятельности органов власти и управления и исполнителей, практические рекомендации по совершенствованию действий властных структур или управленческие технологии, готовые к внедрению.

В октябре - декабре 2012 г. нами был предпринят социальный аудит работы органов местного самоуправления Березовского городского округа по развитию муниципальной системы общего образования. Процедура аудита включает четыре этапа [2]. 
На первом этапе был проведен предметно-содержательный анализ документов - Стратегического плана развития Березовского городского округа до 2015 г. (далее - Стратегический план) и городской целевой программы «Развитие системы образования Березовского городского округа на 2011-2015 гг.» (далее - Программа).

В Стратегический план был включен проект, направленный на развитие общего образования и получивший название «Общее образование как система (детских) социально значимых проектов". Цель данного проекта - «повышение уровня социальной компетенции граждан в возрасте до 18 мет на основе реализации комплекса мер, обеспечивающих адекватность современному уровню знаний, доступность, безопасность, непрерывность и адаптивность общего и дополнительного образования.

Задачи проекта:

- корректировка технологий преподавания с целью обеспечения успешности и высокой самооценки учащегося как основы противостояния влиянию негативных факторов социальной среды;

- формирование позитивной социальной активности ребенка, его правовой культуры;

- разработка программ поддержки детских социально значимых проектов;

- повышение доступности и качества услуг дополнительного образования детей и совершенствование их социально-адаптирующих функций;

- концентрация ресурсов, повышение активности и социальной направленности деятельности всех субъектов образования" [7].

Дальнейшей организационной основой достижения задач Стратегического плана в сфере образования стала Программа, обеспечивающая продолжение модернизации образования, последовательность и контроль инвестирования средств местного бюджета и средств социальных партнеров в систему образования, объединение усилий субъектов системы и необходимых ресурсов дмя достижения гмавной цели образования территории: повышения доступности качественного образования, соответствующего требованиям инновационного развития экономики, современным потребностям граждан Березовского городского округа [1]. 
В целом цели и задачи Стратегического плана и Программы соответствуют основным приоритетным направлениям развития образования на федеральном и региональном уровнях. Эти направления включают внедрение новых организационно-правовых форм учреждений образования, обеспечение компетентностного подхода, поддержку одаренных детей, создание прозрачной, открытой системы информирования граждан об образовательных услугах и образовательной среды, обеспечивающей доступность качественного образования для миц с ограниченными возможностями здоровья, создание цемостной системы объективного оценивания качества образования, внедрение современных стандартов, включая условия организации образовательного процесса, подготовку, переподготовку, повышение квалификации персонала.

Однако некоторые задачи в Программе сформулированы недостаточно конкретно, отдельные приоритетные направления указаны только в форме ожидаемых результатов, а есть и такие, что совсем не прописаны. Например, не говорится о возможности использования механизмов частно-государственного партнерства, создании органов самоуправления, поддержке семейного образования.

На втором этапе бымо продиагностировано состояние муниципальной системы общего образования и выявлены проблемы ее развития.

В Березовском городском округе функционирует 17 общеобразовательных учреждений с общим количеством 6728 учеников. В системе общего образования Березовского округа трудятся 1657 работников, из них - 440 педагогов [4].

С 1 сентября 2012 г. 2034 школьника обучаются по новым федеральным государственным стандартам. ДАя качественной реализации стандартов классы оснащены комплектами учебно-лабораторного и спортивного оборудования.

В рамках программы "Доступная среда" проведены работы по устройству пандусов, крылец, туалетных комнат для детей с ограниченными возможностями здоровья. Функционируют два центра дистанционного обучения для детей-инвалидов и часто болеющих детей [8].

Управление образованием проводит опросы учителей и учащихся школ, результаты которых размещаются на сайте [3]. 
ДАя выявления проблем развития муниципальной системы образования было проведено экспертное интервью, в результате которого были установлены положительные тенденции: внедрение информационно-коммуникационных технологий в учебный процесс, введение федеральных государственных образовательных стандартов и т. д. Вместе с тем эксперты отметили недостатки, которые требуется устранить:

1) старение педагогических кадров: "Проблема старения кадров очень актуальна. Сохраняется большое количество преподавателей пенсионного возраста. Аишь небольшой проиент молодых педагогов остаются работать в школен;

2) проблема профессиональной подготовки руководителей образовательных учреждений: "Так же надо пересмотреть систему профессиональной переподготовки управлениев в системе образования. Сейчас руководитель должен быть менеджером, юристом, педагогом, экономистоми;

3) неэффективное использование средств, выделяемых на оборудование: "Зачастую педагоги и руководители просто не владеют информаиией о современных средствах обучения, которые позволяют осуществлять образовательный проиесс в рамках деятельностного подхода, включать детей в проиесс исследования, т. е. выполнять требования компетентностного подхода. Это минилабаратории, модели, макеты, модули. Педагоги приобретают таблииы, схемы, которые хороши при объяснительно-иллюстративном методе, но не позволяют достичь такого эфректа, как включение детей в проектную деятельность";

4) издержки содержания городской цемевой программы "Развитие системы образования Березовского городского округа на 2011-2015 гг.": "В Программе недостаточно учтены такие особенности Березовского городского округа, как близость крупного мегаполиса (Екатеринбурга) и производственная сфера городских предприятий”.

На третьем этапе социального аудита согласно итогам реализации Программы в 2011 г. по отдельным показателям оценивалась эффективность развития муниципальной системы общего образования.

1. Показатели эффективности подпрограммы «Введение федеральных государственных образовательных стандартов»: 
- удельный вес учащихся общеобразовательных учреждений, обучающихся на первой ступени (1-е классы) по федеральным государственным образовательным стандартам - 100\%;.

- доля общеобразовательных учреждений, обеспеченных учебной $и$ итературой в соответствии с требованиями федерального государственного образовательного стандарта начального общего образования - $100 \%$;

- количество общеобразовательных учреждений, в которых разработана и реализуется основная образовательная программа начального общего образования в соответствии с концептуальными идеями федерального государственного образовательного стандарта - 100\%.

Однако не отслежены такие критерии эффективности, как удельный вес детей в общеобразовательных учреждениях, обучающихся в профильных классах на третьей ступени школы; число учреждений, реализующих модели профильного обучения на основе индивидуальных учебных планов; количество школьников, осваивающих программы, построенные с использованием сетевых форм организации учебного процесса.

2. Показатели подпрограммы “Кадры»:

- учителя начальных классов, участвующие в реализации ФГОС начального общего образования и прошедшие курсовую подготовку по его введению - 100\%.

В этом раздеме не отражены удельный вес педагогов, повышающих уровень педагогического мастерства посредством индивидуальных образовательных маршрутов; доля руководящих работников образовательных учреждений, прошедших переподготовку по стандартизированной программе «Менеджмент в образовании"; процент образовательных учреждений, реализующих программы развития профессиональной компетенции педагогических кадров; число педагогов, имеющих финансовую поддержку инновационной деятельности; количество молодых педагогов, прошедших стажировку на базе общеобразовательных учреждений и реализующих инновационные образовательные программы.

3. Показатели подпрограммы «Здоровье детей»:

- образовательные учреждения, в которых используются немедикаментозные формы оздоровления обучающихся, - 100\%; 
- образовательные учреждения, реализующие проекты, обеспечивающие системную работу по формированию культуры здорового и безопасного образа жизни подрастающего покомения, - 100\%;

- школьники, отнесенные по состоянию здоровья к специальной медицинской группе, $-4,6 \%$;

- учащиеся, принявшие участие в обследовании на употребмение ПАВ (поверхностно-активных веществ), - 92\%;

- образовательные учреждения, в которых имеются столовые, соответствующие современным требованиям, $-75 \%$;

- учащиеся образовательных учреждений, которые получают качественное горячее питание, $-92 \%$.

Не были зафиксированы такие показатели эффективности, как доля образовательных учреждений с современной здоровьесберегающей инфраструктурой; число медицинских кабинетов образовательных учреждений, оборудованных в соответствии с требованиями СанПиНа и получивших положительное экспертное заключение; количество детей, занимающихся в школьных спортивных секциях.

4. Показатели подпрограммы "Школьная инфраструктура»:

- ремонт осуществлен в 7 школах (ОУ № 1, 9, 10, 11, 21, 32, 33);

- в 12 средних образовательных учреждениях приобретено новое технологическое оборудование в пищеблоки и \или проведен текущий ремонт пищеблоков;

- в 16 школах приобретено компьютерное оборудование;

- 12,5\% общеобразовательных учреждений имеют современную (модернизированную) инфраструктуру.

В разделе отсутствуют сведения о среднем количестве учащихся общеобразовательных учреждений на один персональный компьютер (ПК); доме учреждений, где есть компьютерные классы с количеством не менее семи ПК, работающих в единой цокальновычислительной сети $(\Lambda \mathrm{BC})$ и имеющих широкополосный доступ к Интернет со скоростью не ниже 2 Мбит/с; числе общеобразовательных учреждений, в которых используются информационные технологии для автоматизации процессов внутришкольного управмения; учреждений, оборудованных в соответствии с Требованиями к условиям ФГОС; школ, имеющих инфраструктуру дмя успешной подготовки учащихся к сдаче норм ГТО. 
5. Показатели подпрограммы «Развитие системы оценки качества образования":

- завершен второй этап реализации целевого проекта муниципальной системы оценки качества образования (далее - МСОКО) "Создание единой системы индикаторов оценки качества образования Березовского городского округа»; модель МСОКО апробируется в базовых образовательных учреждениях, организован городской круглый стол по обобщению итогов и распространению опыта существующей практики среди муниципальных общеобразовательных учреждений округа;

- проведена процедура образовательного аудита по данной теме в 16 муниципальных общеобразовательньх учреждениях (100\%), проведена корректировка Программ развития ОУ;

- проверено качество учебных достижений по математике и русскому языку в 43 классах (100\%);

- произведен мониторинг физического развития учащихся общеобразовательных учреждений (100\%).

Не отслеживаются такие показатели, как уровень освоения (уровень обученности учащихся) программ начальной, основной и средней (полной) ступени общего образования; уровень оценки внеучебньг достижений обучающихся; наличие системы стандартизованных средств измерения качества образования для обеспечения государственно-общественной оценки деятельности общеобразовательных учреждений.

6. Показатели подпрограммы "Одаренные дети»:

- количество способных и одаренных детей - победителей и призеров олимпиад, конкурсов, конференций, проведенных на различных уровнях (муниципальном, областном, всероссийском) 173 (35\% от общего количества участвовавших);

- школьники, включенные в систему адресной поддержки одаренных детей, - 350 человек (5\% от общей численности обучающихся в общеобразовательных учреждениях).

7. Показатели подпрограммы "Обеспечение доступной среды жизнедеятельности для миц с ограниченными возможностями здоровья по образовательным учреждениям Березовского городского округа на 2012 г.»:

- внедрение проекта «Инклюзивное образование» совместно с Институтом психологии УрГПУ. 
Нет информации об общеобразовательных учреждениях, где создана универсальная безбарьерная среда, позволяющая обеспечить совместное обучение инвалидов и школьников, не имеющих нарушений развития.

Таким образом, проведенный аудит показал, что результаты реализации Программы отслеживаются бессистемно, что мешает своевременно вносить необходимые корректировки в осуществцяемую работу.

Оценка удовиетворенности населения Березовского городского округа качеством общего образования осуществляется ежегодно. На основе сводных докладов о деятельности органов местного самоуправления городских округов и муниципальных районов, расположенных на территории Свердловской области, за 2010 и 2011 г. [9, 10] нами была составмена таблица.

Удовлетворенность населения Березовского городского округа качеством общего образования в 2010-2011 гг.

\begin{tabular}{|c|c|}
\hline Год & Доля от числа опрошенных \\
\hline 2009 & 68,0 \\
\hline 2010 & 69,0 \\
\hline 2011 & 69,0 \\
\hline
\end{tabular}

В сводном докладе за 2011 г. Березовский округ был отнесен к группе 10 муниципальных образований, показавших наихудшие результаты по показателю удовлетворенности населения качеством общего образования.

Четвертый этап социального аудита предполагал разработку системы практических рекомендаций по совершенствованию деятельности органов местного самоуправления в сфере общего образования, повышению социальной эффективности их деятельности.

Дия решения выявленных проблем эксперты предложили ряд механизмов, которые должны способствовать развитию системы общего образования в округе:

1) совершенствование кадровой работы: "подготовка, "выращивание” собственных педагогов, открытие педагогических классов, поддержка учительских династий”; 
2) решение проблемы профессиональной подготовки руководителей: "создание управленческого резерва (на уровне области), управленческие практикумьи;

3) повышение информированности педагогов о современных средствах обучения, повышение их квалификации: "создание методических пособий для педагогов, раскрывающих сущность деятельностных технологий, проведение практикумов, исследований, научно-практических конферениий”.

4) внесение дополнений в городскую целевую программу "Развитие системы образования Березовского городского округа на 2011-2015 гг.": "создание совместных образовательных проектов сгородами Свердловской области, использование возможностей города Екатеринбурга в образовательных иелях".

Однако эти предложения направлены в основном на устранение текущих проблем и преодоление негативных тенденций в муниципальной системе образования. Они не нацелены на вызовы завтрашнего дня, на стратегию опережения. Между тем современная система образования должна ориентироваться на будущие потребности экономики, на приоритет воспитания. "Целями нового этапа развития образования должны стать: обеспечение позитивной социализации и учебной успешности каждого ребенка, усиление вклада образования в инновационное развитие России, ответ на вызовы изменившейся культурной, социальной и технологической среды... Наибомее реалистичным сценарием развития сферы образования и социализации в среднесрочной перспективе является модернизация шкомы, направленная на расширение ее социально-культурных функций, обновление содержания образования, умучшение преподавания в соответствии с новыми вызовами цивилизации" [11, с. 269].

Таким образом, в целях развития муниципальной системы образования необходимо перенести акцент с укрепления инфраструктуры на достижение нового качества образовательных услуг.

\section{Митература}

1. Городская целевая программа "Развитие системы образования Березовского городского округа на 2011-2015 гг.». [Электрон. ресурс]. Режим доступа: http://www.bergorono.ru/upload/ programma_razvitiya_obrazovaniya_bgo.doc (дата обращения 01.03.2013). 
2. Зерчанинова Т. Е. Процедура социального аудита деятельности органов местного самоуправцения // Социум и вцасть. 2010. № 4. C. 21-25.

3. Исследования в системе образования [Электрон. ресурс]. Режим доступа: http://www.bergorono.ru/issledovaniya/ (дата обращения 28.02.2013).

4. Комплекс мер по модернизации общего образования Березовского городского округа [Электрон. ресурс]. Режим доступа: http://www.bergorono.ru/2012-41.doc (дата обращения 28.02.2013).

5. Концепция российской модели социального аудита. М.: Академия труда и социальных отношений, 2007. 24 с. [Электрон. peсурс]. Режим доступа: http://www.globecsi.ru/Articles/2007/ Popov.pdf (дата обращения 19.07.2012).

6. Новиков А. М., Новиков Д. А. Методология [Электрон. ресурс]. М.: СИНТЕГ, 2007. 668 с. Режим доступа: http://www.mtas.ru/ uploads/methodology.htm (дата обращения 11.08.2012).

7. Об утверждении стратегического плана развития Березовского городского округа до 2015 года (этап 1): Решение Думы Березовского городского округа от 16 марта 2006 г. № 184 // Березовский рабочий. 2006. 8 июня.

8. Основные итоги социально-экономического развития Березовского городского округа за 2012 г. [Электрон. ресурс]. Режим доступа: http://Березовский.pф/blog_mjera/42.html (дата обращения 02.03.2013).

9. Сводный доклад о результатах мониторинга эффективности деятельности органов местного самоуправления городских округов и муниципальных районов, расположенных на территории Свердловской области за 2010 г. [Электрон. ресурс]. Режим доступа: http://economy.midural.ru/uploads/document/1/svodny_doklad_mo _2010.pdf (дата обращения 28.02.2013).

10. Сводный доклад о резумьтатах мониторинга эффективности деятельности органов местного самоуправления городских округов и муниципальных районов, расположенных на территории Свердловской области за 2011 г. [Электрон. ресурс]. Режим доступа: http://www.midural.ru/100034/100089/100401/ (дата обращения 28.02.2013) 
11. Стратегия - 2020: Новая модель роста - новая социальная политика. Итоговый доклад о результатах экспертной работы по актуальным проблемам социально-экономической стратегии России на период до 2020 года. 864 с. [Эмектрон. ресурс]. Режим доступа: http://2020strategy.ru/documents/32710234.html (дата обращения 28.02.2013).

12. Штомпка П. Социология социальных изменений. М.: Аспект Пресс, 1996. 664 с.

13. Юдин Э. Г. Развитие [Электрон. ресурс] // Большая сов. энцикл.: в 30 т. М.: Сов. энцикл., 1969-1978. Режим доступа: http://slovari.yandex.ru/ \%D0\%BA\%D0\%BD\%D0\%B8\%D0\%B3\%D0 \%B8/\%D0\%91\%D0\%A1\%D0\%AD/\%D0\%A0\%D0\%B0\%D0\%B7\%D0\% B2\%D0\%B8\%D1\%82\%D0\%B8\%D0\%B5\%20(\%D1\%84\%D0\%B8\%D0\% $\mathrm{BB} \% \mathrm{D0} \% \mathrm{BE} \% \mathrm{D} 1 \% 81 \% \mathrm{D0} \% \mathrm{BE} \% \mathrm{D} 1 \% 84$. )/ (дата обращения 26.07.2012).

\section{References}

1. City Program "Development of the educational system Berezovsky urban district for 2011-2015" [Electron. resource]. URL: http:/ /www.bergorono.ru/upload/programma_razvitiya_obrazovaniya _bgo.doc (date accessed 01.03.2013).

2. Zerchaninova T. E. // Socium i vlast'. 2010. № 4. P. 21-25.

3. Research in Education [Electron. resource]. URL: http:// www.bergorono.ru/issledovaniya/ (date accessed 28.02.2013).

4. The package of measures to modernize the general education Berezovsky urban district [Electron. resource]. URL: http://www.bergorono.ru/2012-41.doc (date accessed 28.02.2013).

5 . The concept of the Russian model of social audit [Electron. resource]. M.: Akademija truda i social'nyh otnoshenij, 2007. 24 p. URL: http://www.globecsi.ru/Articles/2007/Popov.pdf (date accessed 19.07.2012).

6. Novikov A. M., Novikov D. A. Methodology [Electron. resource]. M.: SINTEG, 2007. 668 p. URL: http://www.mtas.ru/uploads/methodology.htm (date accessed 11.08.2012).

7. Zerchaninova T. E. // Berjozovskij rabochij. 2006. June 8.

8. The main results of the socio-economic development of the urban district of Berezovsky 2012 [Electron. resource]. URL: http://Berjozovskij.rf/blog_mjera/42.html (date accessed 02.03.2013). 
9. Consolidated report on the results of monitoring the effectiveness of local government urban districts and municipal districts, located in the Sverdlovsk region in 2010 [Electron. resource]. URL: http://economy.midural.ru/uploads/document (date accessed 28.02.2013).

10. Consolidated report on the results of monitoring the effectiveness of local government urban districts and municipal districts, located in the Sverdlovsk region in 2011 [Electron. resource]. URL: http://economy.midural.ru/uploads/document (date accessed 28.02.2013).

11. Strategy 2020 [Electron. resource]. URL: http://2020strategy.ru/ documents/32710234.html (date accessed 28.02.2013).

12. Shtompka P. Sociology of Social Change. M.: Aspekt Press, 1996. 664 p.

13. Judin Je. G. Development // Bol'shaja sovetskaja jenciklopedija: v 30 t. M.: "Sovetskaja jenciklopedija", 1969-1978. [Electron. resource]. URL: http: / / slovari.yandex.ru/ \%D0\%BA\%D0\%BD\%D0\%B8\%D0\%B3\%D0 \%B8/\%D0\%91\%D0\%A1\%D0\%AD/\%D0\%A0\%D0\%B0\%D0\%B7\%D0\% B2\%D0\%B8\%D1\%82\%D0\%B8\%D0\%B5\%20 (\%D1\%84\%D0\%B8\%D0\% $\mathrm{BB} \% \mathrm{D} 0 \% \mathrm{BE} \% \mathrm{D} 1 \% 81 \% \mathrm{D} 0 \% \mathrm{BE} \% \mathrm{D} 1 \% 84$.) (date accessed 26.07.2012). 